\title{
Quantitative evaluation of the sustainability or unsustainability of municipal solid waste options in Tabriz, Iran
}

\author{
J. Phillips ${ }^{1} \cdot$ M. Gholamalifard ${ }^{2}$
}

Received: 23 September 2015/Revised: 29 December 2015/Accepted: 12 April 2016/Published online: 27 April 2016

(C) Islamic Azad University (IAU) 2016

\begin{abstract}
Iran has been seeking to develop fully functional waste management strategies to address the problem of its rapidly growing cities. This requires proper evaluation to determine the most appropriate strategies to meet the goals of sustainable waste management. Environmental Impact Assessment is capable of contributing towards this goal. However, such assessments tend to involve a qualitative approach in the evaluation of the sustainability or unsustainability of potential options. Therefore, a suitable quantitative approach to evaluate sustainability/unsustainability is necessary. The paper applies a mathematical model to evaluate the sustainability of unmitigated options for a municipal solid waste disposal site in Tabriz, Iran. This was based upon rapid impact assessment matrix evaluation of the options. The model's application determines whether the options are sustainable or unsustainable. The model application results indicate that all of the options were considered as unsustainable in an unmitigated state. The results for Tabriz were then compared and contrasted with results obtained by the authors for another MSW disposal site near Tehran. Based on this, there are questions as to the potential value of current waste management strategies. The paper concludes by stating that economic costs are the largest single barrier to achieving sustainable waste management. Furthermore, it is important to develop solutions which disposes and
\end{abstract}

M. Gholamalifard

gholamalifard@gmail.com

1 Universidad EAN, Campus El Nogal: Cl 79 \# 11-45, Sede Av. Chile: Cl 72 \# 9-71, Bogotá, Colombia

2 Department of Environment, Faculty of Natural Resources, Tarbiat Modares University, P.O. Box 46414-356, Noor, Mazandaran 46417-76489, Iran manages waste in a manner conducive to the long-term sustainability of the environment-human relationship.

Keywords Mathematical model - Rapid impact assessment matrix $\cdot$ Sustainability science $\cdot$ Waste management

\section{Introduction}

\section{Waste management in Iran}

One of the biggest environmental problems for local authorities in Iran is the production and containment of urban waste. This is due to the lack of proper waste management practices, which always results in negative impacts. Impacts caused include those related to: human health; water resources; fisheries; agriculture; tourism; trade; and food security. In developing countries, such as Iran, open dumping is the most common approach used in rapidly growing cities, because it is the least expensive to implement (Wang and Nie 2001; Troschinetz and Mihelcic 2009).

Solid waste can impact the environment in various ways and depending upon how it is managed. Integrated solid waste management using the $3 \mathrm{R}$ approach (reduce, reuse and recycle) has become a common and essential approach for policy makers and practitioners. This approach covers all aspects of waste generation and management from: collection through segregation; transportation; treatment; and disposal. Therefore, this minimizes the amount of waste from generation to disposal (Memon 2010; UNEP 2011).

In the recent years, municipal solid waste (MSW) has been one of the most important environmental concerns 
throughout regions of Iran (Gholamalifard et al. 2014). Most of the landfills in northern Iran are primarily open dumps without leachate or gas recovery systems. The landfills therefore operate below the recommended standards for sanitary practice (Chaudhary 2008). They also tend to be located in ecological or hydrologically sensitive areas. Iran's Department of Environment has identified improvements to the overall performance of the MSW system as one of its strategic priorities. For sound MSW management to occur, it requires reliable data concerning the current state of MSW in an area. To this end, Hassanvand et al. (2008) collected and analysed data from various municipal regions, to determine the current situation of MSW management in Iran on a range of issues. These included: average rate of waste generation; physical composition of waste; and types of disposal methods used.

Hassanvand et al.'s (2008) results showed that the total MSW generated in all of Iran's municipal regions was $10,370,798$ tons/year. This equates to an average generation rate of $0.64 \mathrm{~kg}$ per person/day. Furthermore, only $6 \%$ of MSW was recycled, $10 \%$ was treated at organic waste (composting) plants, and about $84 \%$ were disposed in landfills. Hassanvand et al. (2008) then went onto compare the composition of MSW in Iran to other countries. This highlighted the fact that Iran's situation was consistent with those experienced in low-income countries.

The majority of MSW generated in Iran is organically based. Therefore, there is a significant potential to use composting. However, the current level of MSW services provided in Iran varies significantly. The most significant problems are experienced in large and intermediate urban areas. Iran's smaller cities currently only have the most basic waste management services.

There has been considerable progress in some of the largest cities in recent years. Waste collection has gone from manual carts to a fully functional waste management system. One such city seeking a functional waste management system is Tabriz. To achieve this goal, an EIA evaluation of the available waste management options for Tabriz was conducted. Based on this EIA, the authors of this paper conducted further analysis, to ascertain the potential sustainability or unsustainability for proposed (unmitigated) options for the Tabriz MSW disposal site. From this, the best potential option for sustainable municipal waste management in Tabriz will be indicated.

\section{Tabriz MSW disposal site}

Tabriz is the largest industrial city in North West of Iran (see: Fig. 1), with a population of approximately 1.6 million. The city currently generates 1200 tons/day of waste, which equates to an average of $0.71 \mathrm{~kg}$ per person/day. The waste is currently disposed at the Tabriz MSW disposal site using an open dumping approach.

In total, $70 \%$ of the total waste processed at the site is wet wastes. This predominantly consists of wastes from domestic activities and very small quantities from

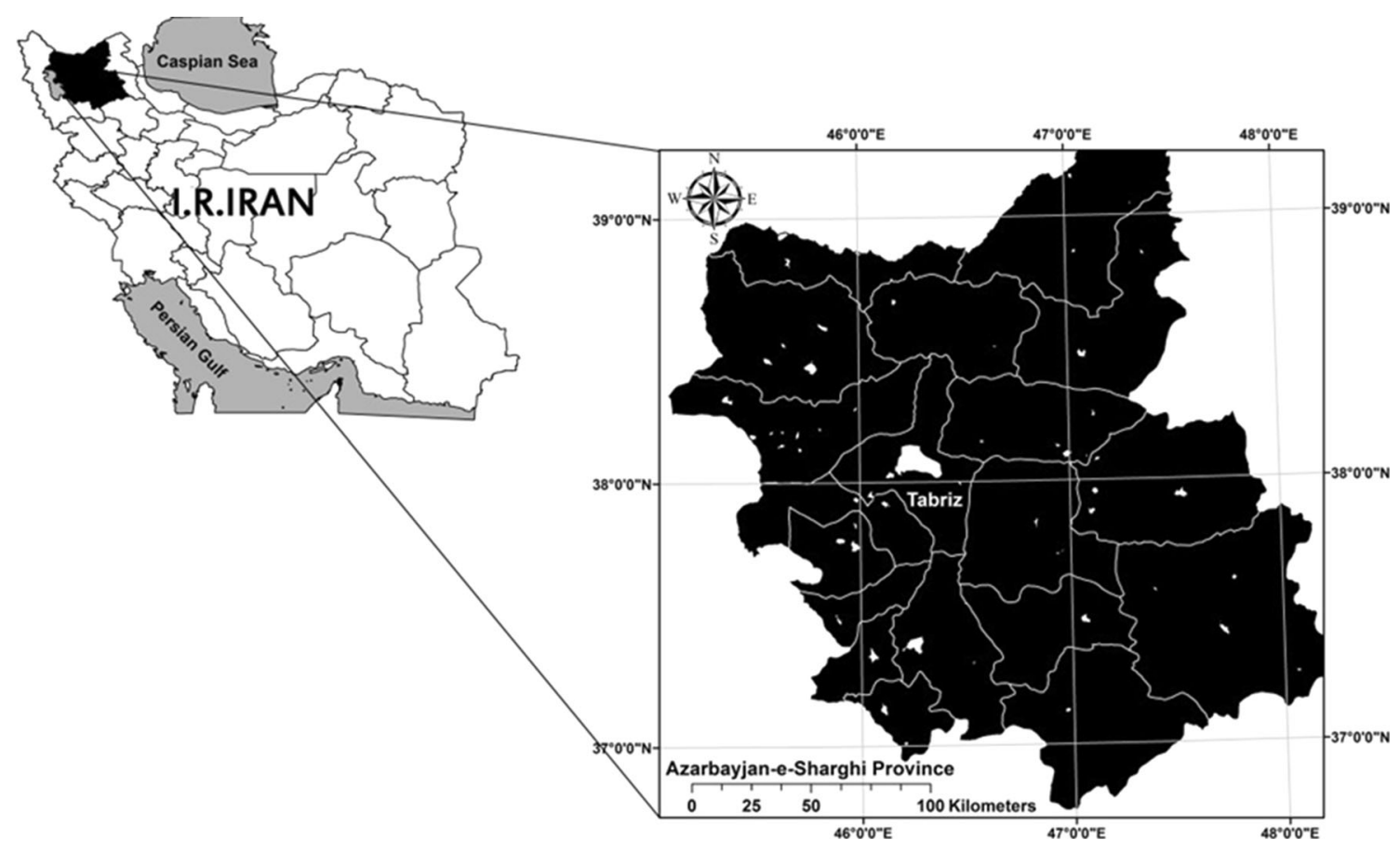

Fig. 1 Location map for Tabriz, Iran 
commercial, industrial and other activities. Because of the open dumping method used, uncontrolled accumulation of wastes is generated which are dumped into a valley. This has consequently caused numerous detrimental impacts to the local environment and community to occur.

The most significant impacts are from leachate generation and contamination and air pollution. Significant quantities of leachate are generated because of wastes degrading which have a high moisture content. The leachate infiltrates through the natural barrier underneath the dumpsite into existing dents or constructed ponds, where it resides without any treatment. This is because of the lack of membranes or geotextiles to prevent leachate penetration. As a consequence, the leachate contaminates the soil and groundwater. The other significant impacts are from odours and greenhouse gas emissions because of the exposure of the wastes to the open environment. This exposure causes the waste to degrade and decompose through physio-chemical and biological processes. This has resulted in spontaneous combustion of wastes because of the gases produced, which includes methane.

\section{Outline of study}

This paper intends to apply a revised mathematical model (re: Phillips 2015) to the original results of an Environmental Impact Assessment (EIA), as conducted by Taheri et al. (2014) using the rapid impact assessment matrix (RIAM) method. The EIA for the Tabriz MSW disposal site evaluated the environmental and anthropospheric impacts of four potential (unmitigated) options for waste disposal and management. The purpose of applying the model to the RIAM evaluation was to determine the sustainability or unsustainability of these options. From this, the best potential option for sustainable municipal waste management in Tabriz will be indicated. The study occurred at the authors' current affiliated institutions between April and August 2014.

\section{Materials and methods}

\section{Mathematical model of sustainability}

The model fundamentally consists of the following key steps in relation to its application to the RIAM: (1). obtain relative ES scores and totals for the designated parameters and categories for each option; (2). calculate indicated values for the Environment (E) and Human Needs and Interests (HNI) for each option; (3). determine whether sustainability or unsustainability is occurring based upon obtained values of $\mathrm{E}$ and HNI for each option; and (4). if sustainability (S) is deemed to be occurring, determine the indicated $\mathrm{S}$ value and
$\mathrm{S}$ level for the option. A simplified methodology is provided in Fig. 2, showing the steps for applying the model to the RIAM methodology. This is based upon revisions of the model's mathematics and application, as stated in Phillips (2015). An example calculation, demonstrating the model's application to the RIAM results for open dumping (Option 1), is provided in Table 1.

The model fundamentally states that for sustainability (S) to be deemed as occurring, the obtained indicated value of $\mathrm{E}$ must be greater than the obtained indicated value of HNI. This means that the potential obtained value of $\mathrm{S}$ would occur within a range of 0.001-1.000. Where the obtained value of $\mathrm{E}$ is less than the obtained value of $\mathrm{HNI}$, then this indicates unsustainability.

In respect of the RIAM evaluation, conducted by Taheri et al. (2014) for the Tabriz MSW disposal site, four options for waste management were evaluated. These were: (1). open dumping (the current method); (2). sanitary landfill; (3). composting; and (4). recycling. The options were evaluated in an unmitigated state-this means the option's unaltered state/condition before the implementation of an environmental management plan (EMP). Therefore, there is an opportunity to evaluate the impact of humans upon the environment, in relation to developing options for sustainable waste disposal and management.

\section{Results and discussion}

\section{Overview of results}

The original ES values obtained by Taheri et al. (2014) are shown in Table 2. Table 2 also includes the relative ES values obtained, as part of the model application to the RIAM results (Fig. 2a, Step 4).

Table 3 shows the final model results for the unmitigated options at Tabriz MSW disposal site. As indicated, all of the options in the unmitigated conditions were deemed to be unsustainable. In the case of open dumping, this was to be expected. However, why this is the case for the potential alternatives of sanitary landfill, composting and recycling, needs to be explored further. Therefore, it is necessary to contrast the model's results to the original RIAM results (Tables 3, 2, respectively). This will explain as to why all of the options were indicated to be unsustainable.

\section{Analysis of results}

\section{Option 1: open dumping}

The obtained E-value was 0.250 , and the obtained HNIvalue was 0.585 (Table 3 ). This indicates that the option is unsustainable, as the value of $\mathrm{E}$ is less than the value of 
(a)

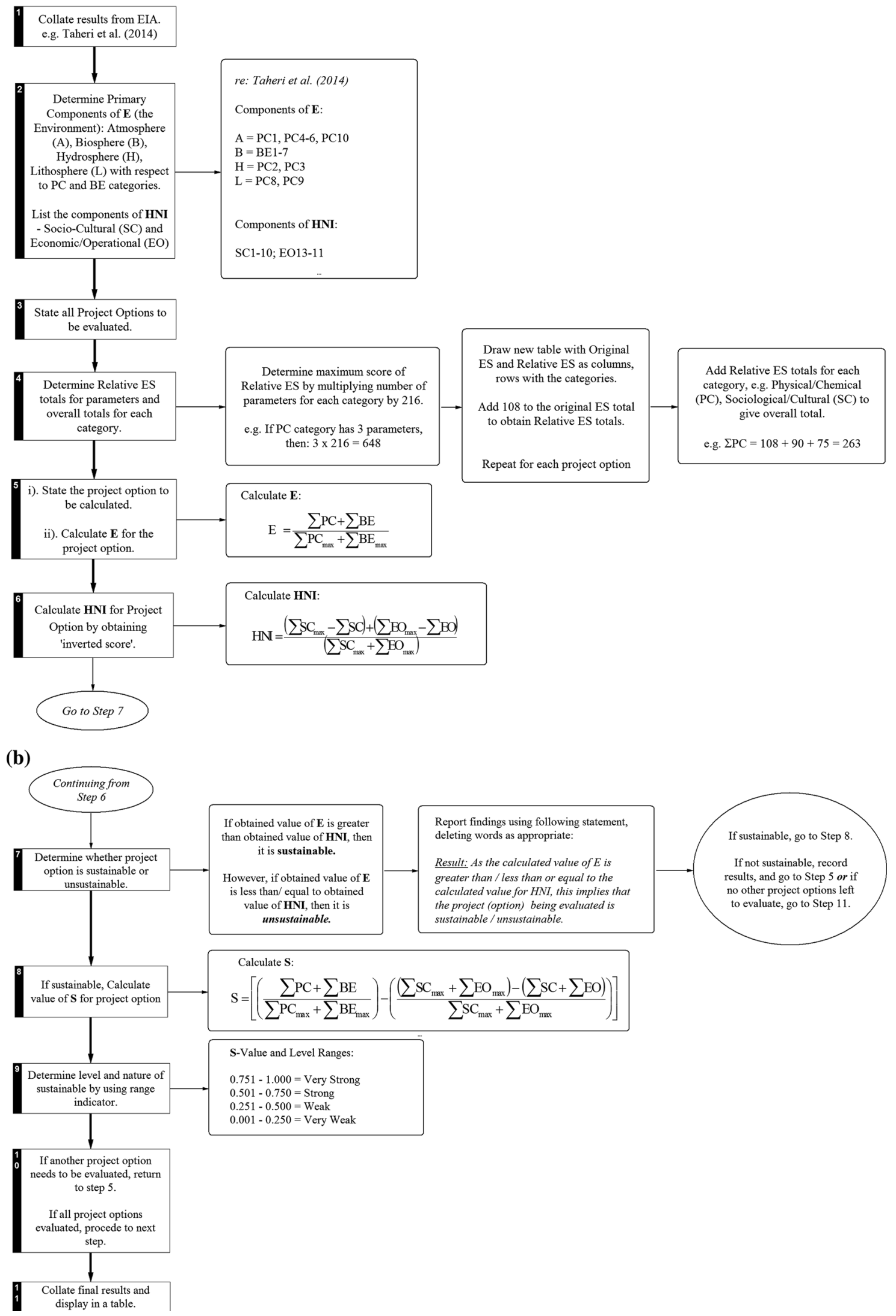


4Fig. 2 Model application methodology to the RIAM, based on Phillips (2015). a Steps 1-6 and b Steps 7-11

HNI (Fig. 2b, Step 7). The reasons for this are highlighted in Table 2.

Of the 38 categories evaluated (Table 2), 30 were evaluated with negative ES values. Of these 30 categories, 21 had ES values of -27 or greater. The majority of the negative impacts occurred within the PC and BE categories and contained the most significant negative impacts. Only topography and land-use shape (PC9) was evaluated as not having a negative impact, with an ES value of 0 (zero) which indicated no change. The only positive impacts from the option occurred in relation to Job opportunities (SC9) and Revenues generated (EO1).

The significant negative impacts upon the environment, coupled with the high impact of human needs and activities, explain for why the corresponding $\mathrm{E}$ and the HNI-values were obtained. The option, in an unmitigated state, causes significant damage to the local environmenthuman system. As a result, this damages and degrades the long-term sustainability of the environment-human relationship. Even with an EMP in place, it is doubtful that the situation could be remedied so that it is conducive with sustainability. This is because of the significant economic costs of management. Furthermore, the negative environmental impacts, in respect of odours, dust, leachate, etc., would still continue to a significant degree.

\section{Option 2: sanitary landfill}

This option had an obtained E-value of 0.383 and an obtained HNI-value of 0.534 (Table 3). This was an improvement compared to Option 1, but still indicated

Table 1 Example model calculation for Option 1 (open dumping) for the Tabriz MSW disposal site

\begin{tabular}{|c|c|c|}
\hline Stage & Action & Outcome \\
\hline \multirow[t]{3}{*}{$\begin{array}{l}\text { (a) Determination of } \\
\text { components of } \mathrm{S}\end{array}$} & (1) Components of E (Step 2) & $\begin{array}{l}\mathrm{A}=\mathrm{PC} 1, \mathrm{PC} 4-6, \mathrm{PC} 10 \\
\mathrm{~B}=\mathrm{BE} 1-7 \\
\mathrm{H}=\mathrm{PC} 2, \mathrm{PC} 3 \\
\mathrm{~L}=\mathrm{PC} 8, \mathrm{PC} 9\end{array}$ \\
\hline & (2) Components of HNI (Step 2) & $\mathrm{HNI}=\mathrm{SC} 1-10 ; \mathrm{EO} 13-11$ \\
\hline & $\begin{array}{l}\text { (3) Determination of maximum possible } \\
\text { score for } E \text { and HNI components (Step } \\
\text { 4) }\end{array}$ & $\begin{array}{l}\mathrm{PC}_{\text {max }}=10 \times 216=2160 \\
\mathrm{BE}_{\max }=7 \times 216=1512 \\
\mathrm{SC}_{\max }=10 \times 216=2160 \\
\mathrm{EO}_{\max }=11 \times 216=2376 \\
E_{\max }=\mathrm{PC}_{\max }+\mathrm{BE}_{\max }=2160+1512 \\
\mathrm{HNI}_{\max }=\mathrm{SC}_{\max }+\mathrm{EO}_{\max }=2160+2376\end{array}$ \\
\hline
\end{tabular}

(b) Evaluate $\mathrm{S}$ for option 1 -open dumping
Phillips (2015)

$S=\left[\left(\frac{\sum E}{\sum E_{\max }}\right)-\left(\frac{\sum \mathrm{HNI}_{\max }-\sum \mathrm{HNI}}{\sum \mathrm{HNI}_{\max }}\right)\right] \equiv E-\mathrm{HNI}$

For RIAM

$S=\left[\left(\frac{\sum \mathrm{PC}+\sum \mathrm{BE}}{\sum \mathrm{PC}_{\max }+\sum \mathrm{BE}_{\max }}\right)-\left(\frac{\left(\sum \mathrm{SC}_{\max }+\sum \mathrm{EO}_{\max }\right)-\left(\sum \mathrm{SC}+\sum \mathrm{EO}\right)}{\sum \mathrm{SC}_{\max }+\sum \mathrm{EO}_{\max }}\right)\right]$

(1) Calculate E (Step 5)

Determine $E$ within range $0 \leq E \leq 1$

$E=\left(\frac{\sum \mathrm{PC}+\sum \mathrm{BE}}{\sum \mathrm{PC}_{\max }+\sum \mathrm{BE}_{\max }}\right) \rightarrow \mathrm{E}=\left(\frac{485+432}{2160+1512}\right)$

$E=0.250$

(2) Calculate HNI (Step 6)

Determine HNI within range $0 \leq \mathrm{HNI} \leq 1$ (Step $4 \mathrm{a}-\mathrm{b})$

$\mathrm{HNI}=\frac{\left(\sum \mathrm{SC}_{\max }+\sum \mathrm{EO}_{\max }\right)-\left(\sum \mathrm{SC}+\sum \mathrm{EO}\right)}{\sum \mathrm{SC}_{\max }+\sum \mathrm{EO}_{\max }}$

$\mathrm{HNI}=\frac{(2160+2376)-(786+1086)}{2160+2376}$

$\mathrm{HNI}=0.585$

(3) Determine whether S occurs and report findings (Step 7)
$E=0.250 ; \mathrm{HNI}=0.585$

Result As the calculated value of $E$ is less than/equal to the calculated value for HNI, this implies that the project option being evaluated is potentially unsustainable 
Table 2 The ES values for options at the Tabriz MSW disposal site

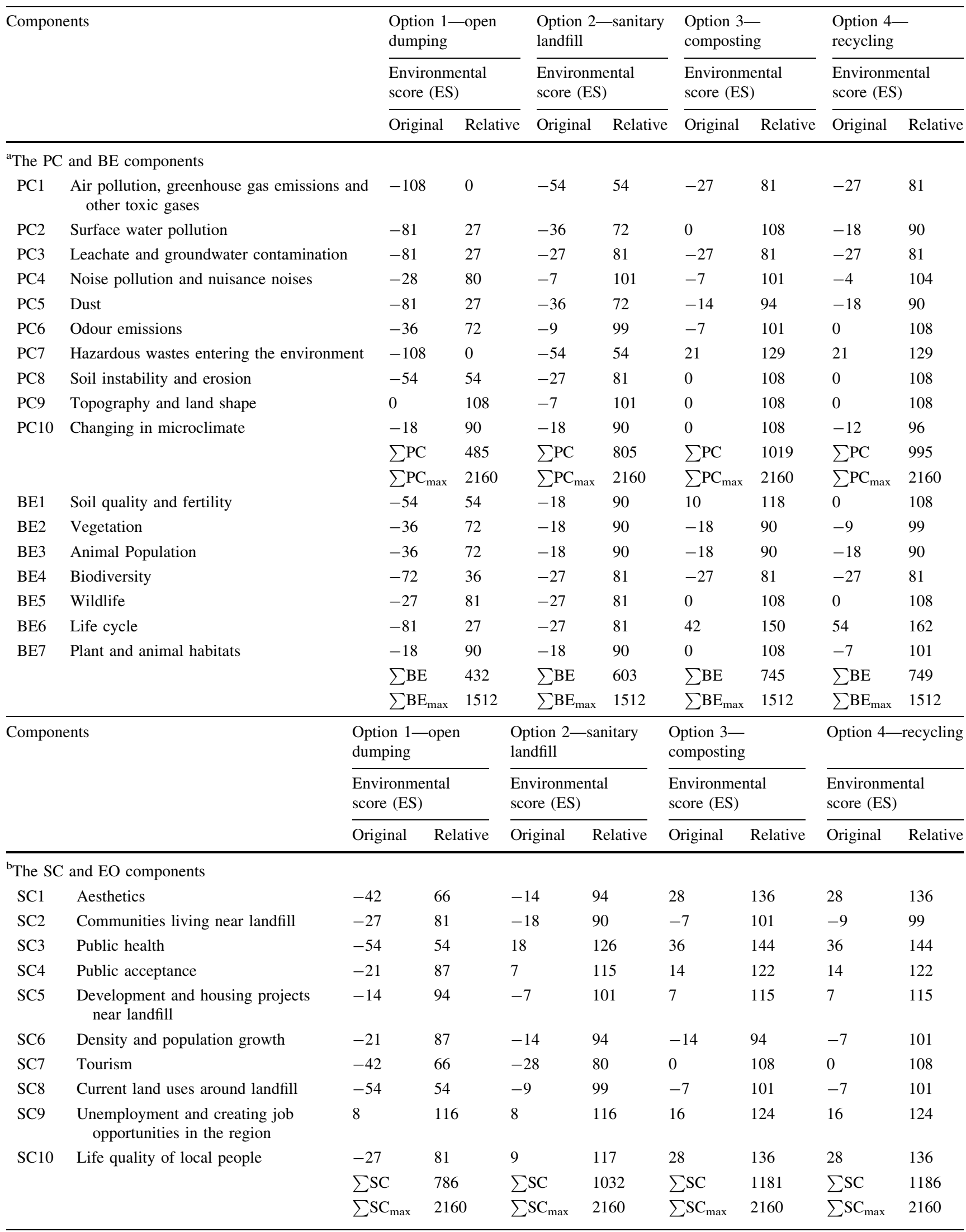


Table 2 continued

\begin{tabular}{|c|c|c|c|c|c|c|c|c|c|}
\hline \multicolumn{2}{|c|}{ Components } & \multirow{2}{*}{\multicolumn{2}{|c|}{$\begin{array}{l}\text { Option 1-open } \\
\text { dumping }\end{array}$}} & \multirow{2}{*}{\multicolumn{2}{|c|}{$\begin{array}{l}\text { Option 2-sanitary } \\
\text { landfill } \\
\text { Environmental } \\
\text { score (ES) }\end{array}$}} & \multirow{2}{*}{\multicolumn{2}{|c|}{$\begin{array}{l}\text { Option 3- } \\
\text { composting } \\
\text { Environmental } \\
\text { score (ES) }\end{array}$}} & \multirow{2}{*}{\multicolumn{2}{|c|}{$\begin{array}{l}\text { Option 4-recycling } \\
\text { Environmental } \\
\text { score (ES) }\end{array}$}} \\
\hline & & & & & & & & & \\
\hline & & Original & Relative & Original & Relative & Original & Relative & Original & Relative \\
\hline EO1 & $\begin{array}{l}\text { Revenues of local communities from } \\
\text { landfill activities }\end{array}$ & 4 & 112 & 4 & 112 & 24 & 132 & 24 & 132 \\
\hline $\mathrm{EO} 2$ & $\begin{array}{l}\text { Costs involved during the process of } \\
\text { dumping to private land }\end{array}$ & -24 & 84 & -24 & 84 & -24 & 84 & -24 & 84 \\
\hline $\mathrm{EO} 3$ & Costs of transferring waste to landfill & -7 & 101 & -7 & 101 & -7 & 101 & -7 & 101 \\
\hline $\mathrm{EO} 4$ & Costs of paying the workers' rights & -7 & 101 & -7 & 101 & -7 & 101 & -7 & 101 \\
\hline EO5 & $\begin{array}{l}\text { Costs of administrative, operating and } \\
\text { maintenance }\end{array}$ & -28 & 80 & -28 & 80 & -28 & 80 & -14 & 94 \\
\hline EO6 & Costs of providing public health & -28 & 80 & -28 & 80 & -28 & 80 & -28 & 80 \\
\hline EO7 & $\begin{array}{l}\text { Costs involved in recycling and reuse } \\
\text { of municipal solid wastes }\end{array}$ & 0 & 108 & 0 & 108 & -12 & 96 & -12 & 96 \\
\hline EO8 & $\begin{array}{l}\text { Revenues from recycled and reused } \\
\text { municipal solid waste }\end{array}$ & 0 & 108 & 0 & 108 & 30 & 138 & 45 & 153 \\
\hline EO9 & Costs for the collection of leachate & 0 & 108 & -14 & 94 & -14 & 94 & -14 & 94 \\
\hline EO10 & Costs for the composting & 0 & 108 & 0 & 108 & -12 & 96 & 0 & 108 \\
\hline \multirow[t]{3}{*}{ EO11 } & Revenues of composting & 0 & 108 & 0 & 108 & 30 & 138 & 0 & 108 \\
\hline & & $\sum E O$ & 1098 & $\sum \mathrm{EO}$ & 1084 & $\sum E O$ & 1140 & $\sum \mathrm{EO}$ & 1151 \\
\hline & & $\sum \mathrm{EO}_{\max }$ & 2376 & $\sum E O_{\max }$ & 2376 & $\sum \mathrm{EO}_{\max }$ & 2376 & $\sum \mathrm{EO}_{\max }$ & 2376 \\
\hline
\end{tabular}

Table 3 Obtained model results for Tabriz MSW disposal site

\begin{tabular}{|c|c|c|c|c|}
\hline & Option 1 (open dumping) & Option 2 (sanitary landfill) & Option 3 (composting) & Option 4 (recycling) \\
\hline \multicolumn{5}{|l|}{ Relative ES } \\
\hline$\sum \mathrm{PC}$ & 485 & 805 & 1019 & 995 \\
\hline$\sum \mathrm{PC}_{\max }$ & 2160 & 2160 & 2160 & 2160 \\
\hline$\sum \mathrm{BE}$ & 432 & 603 & 745 & 749 \\
\hline$\sum \mathrm{BE}_{\max }$ & 1512 & 1512 & 1512 & 1512 \\
\hline$\sum \mathrm{SC}$ & 786 & 1032 & 1181 & 1186 \\
\hline$\sum \mathrm{SC}_{\max }$ & 2160 & 2160 & 2160 & 2160 \\
\hline$\sum E O$ & 1098 & 1084 & 1140 & 1151 \\
\hline$\sum E O_{\max }$ & 2376 & 2376 & 2376 & 2376 \\
\hline \multicolumn{5}{|l|}{ Model } \\
\hline$\sum E$ & 0.250 & 0.383 & 0.480 & 0.475 \\
\hline$\sum \mathrm{HNI}$ & 0.585 & 0.534 & 0.488 & 0.485 \\
\hline Sustainable/unsustainable & $\begin{array}{l}E \leq \mathrm{HNI} \leftrightarrow \mathrm{S} \leq 0 \\
\text { Unsustainable }\end{array}$ & $\begin{array}{l}E \leq \mathrm{HNI} \leftrightarrow \mathrm{S} \leq 0 \\
\text { Unsustainable }\end{array}$ & $\begin{array}{l}E \leq \mathrm{HNI} \leftrightarrow \mathrm{S} \leq 0 \\
\text { Unsustainable }\end{array}$ & $\begin{array}{l}E \leq \mathrm{HNI} \leftrightarrow \mathrm{S} \leq 0 \\
\text { Unsustainable }\end{array}$ \\
\hline$S$ value & - & - & - & - \\
\hline$S$ level & - & - & - & - \\
\hline
\end{tabular}

unsustainability as the E-value was less than the HNI-value (Fig. 2b, Step 7). The improvement in the E- and HNIvalues, compared to Option 1, was +0.113 and -0.051 , respectively. As shown in Table 2, the majority of the impacts continue to be negative in nature, which explains why the option is indicated as unsustainable.

Whilst the severity of negative impacts decreased, there were still a considerable number of parameters with 
detrimental impacts indicated. There were some positive impacts in relation to: Public acceptance (SC4); Job opportunities (SC9), Life quality of local people (SC10); and Revenues generated (EO1). Impact management and mitigation may further improve the situation, particularly in relation to environmental aspects and some social aspects. However, management and mitigation is costly, and it is unclear whether or not the cost-benefit ratio for this option would make it viable.

Nevertheless, from the sustainability perspective, the option is not viable, even if a management plan was in place. This is because in order to make the option sustainable in the long term, it would require a very significant EMP. Whilst this may improve the environmental and social benefits to the local area, it would be at a significant economic cost. This cost would be in relation to implementation and maintenance to the required standards necessary, as well as having no or little tangible economic benefit to local community.

\section{Option 3: composting}

The obtained E-value for this option was 0.480, and the obtained HNI-value was 0.488 (Table 3 ). This consequently indicated unsustainability as the E-value was less than the HNI-value obtained (Fig. 2b, Step 7). Of all the options evaluated, this had the best E-value obtained. However, because of the continuing level of human impacts indicated in the HNI-value, the E-value was not at a level sufficient to produce a result indicating sustainability.

Compared to Option 2, there is a significant improvement in the E-value of +0.097 , representing an increase of $25.3 \%$. There is also a change in the HNI-value of -0.046 compared to Option 2, indicating a slight overall decrease in the impacts caused by human activities. However, the moderate E-value and high HNI-value is a cause for concern, particularly for a stated environmentally beneficial method.

Table 2 indicates that the HNI-value was high because of a significant number of negative values in the EO category. Whilst the option does have benefits in terms of revenue generation, as indicated in the positive values obtained for EO1, EO8 and EO11, the remaining parameters associated with costs are negative. If the relevant parameters are added together, cost-based parameters (EO2-7, EO9-10) have an original ES score of -132 , and revenue-based parameters (EO1, EO8, EO11) have an original ES score of +84 . Taking account that within the EO category costs have eight parameters, and revenues have three parameters-this still indicates that the potential economic costs outweigh the potential economic benefits. However, the costs of the option are offset by some positive environmental and social impacts indicated in Tables 2 and 3.
The most significant positive impacts were in relation to: Life cycle (BE6); Public health (SC3); Life quality of local peoples (SC10); and Aesthetics (SC1). The most significant negative impacts were in relation to: Biodiversity (BE4); Air pollution and greenhouse gases emissions (PC1); and Leachate and groundwater contamination (PC3). A proper structured EMP should be able to remedy these issueshowever, at what cost given the previously highlighted issues? It would appear that for sustainability to be a potential reality, some form of rigorous economic cost control and management is required. It may be that the design and implementation of the option is the issue. Therefore, the option would require revision and re-evaluation in both an unmitigated and mitigated state. However, it may be that management may resolve not only the environmental and social impacts, but also the impacts on economic costs. This is uncertain until a management plan is produced and then evaluated using the RIAM and the model. This would provide the opportunity to compare and contrast the unmitigated and mitigated results obtained.

\section{Option 4: recycling}

The obtained E-value for this option was 0.475, and the obtained HNI-value was 0.485 (Table 3). This indicated that the option was unsustainable as the E-value was less than the HNI-value (Fig. 2b, Step 7). The option has the best HNI-value calculated, indicating reduced impacts from human activities. However, this was only marginally compared to Option 3. The E-value showed a slight decrease compared to Option 3 , indicating slight increase in negative impacts upon the environment. Tables 2 and 3 indicate that similar impacts are evident for this option, as previously outlined for Option 3. These impacts are: economic costs; air pollution; leachate generation; and biodiversity.

Compared to Option 3, some impacts have improved or have reduced impacts-for example: Life cycle (BE6); Revenues from recycled and reused MSW (EO8); and Density and population growth (SC6). The option has however increased negative impacts indicated for: Surface water pollution (PC2); Dust (PC5); and Soil quality and fertility (BE1). Proper management should remedy the issues of negative and no change impacts. However, whether this can be achieved at an acceptable economic cost is not clearly established.

\section{Key factors of unsustainability}

The results have indicated various reasons for the unsustainability of all of the options evaluated. The options were evaluated in an unmitigated state-without an EMP, and it 
Table 4 Model application results for Tabriz compared to the options for a MSW disposal and processing site near Tehran (Gholamalifard et al. 2016)

\begin{tabular}{|c|c|c|c|c|}
\hline & Open dumping & Sanitary landfill & Composting & Recycling \\
\hline \multicolumn{5}{|l|}{ Tabriz } \\
\hline$\sum E$ & 0.250 & 0.383 & 0.480 & 0.475 \\
\hline$\sum \mathrm{HNI}$ & 0.585 & 0.534 & 0.488 & 0.485 \\
\hline Sustainable/unsustainable & $\begin{array}{l}E \leq \mathrm{HNI} \leftrightarrow \mathrm{S} \leq 0 \\
\text { Unsustainable }\end{array}$ & $\begin{array}{l}E \leq \mathrm{HNI} \leftrightarrow \mathrm{S} \leq 0 \\
\text { Sustainable }\end{array}$ & $\begin{array}{l}E \leq \mathrm{HNI} \leftrightarrow \mathrm{S} \leq 0 \\
\text { Sustainable }\end{array}$ & $\begin{array}{l}E \leq \mathrm{HNI} \leftrightarrow \mathrm{S} \leq 0 \\
\text { Sustainable }\end{array}$ \\
\hline$S$ value & - & - & - & - \\
\hline$S$ level & - & - & - & - \\
\hline \multicolumn{5}{|l|}{ Tehran } \\
\hline$\sum E$ & 0.430 & 0.518 & 0.519 & 0.511 \\
\hline$\sum H N I$ & 0.531 & 0.475 & 0.475 & 0.480 \\
\hline Sustainable/unsustainable & $\begin{array}{l}E \leq \mathrm{HNI} \leftrightarrow \mathrm{S} \leq 0 \\
\text { Unsustainable }\end{array}$ & $\begin{array}{l}E \geq \mathrm{HNI} \leftrightarrow \mathrm{S} \geq 0 \\
\text { Sustainable }\end{array}$ & $\begin{array}{l}E \geq \mathrm{HNI} \leftrightarrow \mathrm{S} \geq 0 \\
\text { Sustainable }\end{array}$ & $\begin{array}{l}E \geq \mathrm{HNI} \leftrightarrow \mathrm{S} \geq 0 \\
\text { Sustainable }\end{array}$ \\
\hline$S$ value & - & 0.043 & 0.044 & 0.031 \\
\hline$S$ level & - & Very weak & Very weak & Very weak \\
\hline
\end{tabular}

is not necessarily surprising that some or all of the options were indicated as unsustainable.

In the case of open dumping (Option 1), this would still detrimentally impactful both environmentally and socioeconomically upon the local area, even if managed. Option 2 (sanitary landfill) has indications of significant detrimental impacts, which may prove uneconomic in terms of effective management. Options 3 and 4 (composting and recycling, respectively) indicated potential in relation to their environment and social benefits. However, the issues surrounding economic costs represent a significant drawback in respect of Options 3 and 4. Therefore, economic costs represent the singular biggest barrier in achieving sustainability for Options 2-4.

If costs could be properly managed, then it is possible that sustainability could be achieved. However, this would only be at a very weak level. Whilst management should provide improved environmental and social benefits, there would be a financial cost to achieve this. Both Options 3 and 4 are fully capable of producing a revenue stream which can be used to offset the costs incurred. However, this is insufficient without one or more of the following: further revenue generation; improved cost control; a redesign of the option; and/or the use of another method(s).

\section{Compare and contrast results}

Whilst the options evaluated were in unmitigated state, the results have raised some potential questions concerning the environmental and social credentials of composting and recycling. Both of these options in an unmitigated state were indicated to be unsustainable. This contradicts the widely held view that they are not only environmentally and socially beneficial, but also contribute towards sustainable development. The phrase "reduce, reuse and recycle" has been entrenched into the public conscience, ever since the publication of the Brundtland report "Our Common Future" (WCED 1987). However, the results for Tabriz appear to contradict the potential benefits of composting and recycling. If compared to another waste disposal site near Tehran, evaluated by the authors in a separate study (Gholamalifard et al. 2016), then the issues raised become clearer to understand.

Table 4 indicates that the Tehran site has overall better E-, HNI- and S-values for similar unmitigated options compared to Tabriz. It should be noted that for Tehran, a fourth alternative of incineration was also assessed. However, this was not included in Table 4 as incineration was considered as not a viable option for Tabriz.

The three evaluated alternatives for Tehran to open dumping, using the same current method for Tabriz, all achieved values indicating sustainability. In the case of Tehran, economic costs were far less impactful upon achieving sustainability. Furthermore, a key issue in the results obtained for the alternatives was the dominance of no change $\mathrm{ES}$ values $(\mathrm{ES}=0)$ in the evaluated parameters. This indicates no improvements or decreases in potential/ actual impacts. Therefore, it would seem to be a reasonably undesirable situation for sustainability. However, compared to Tabriz, it represents a significant improvement environmentally, socially and economically. Thus, it would appear that Tabriz could learn from Tehran as to how to manage and process waste effectively.

The fact that both composting and recycling, in the case of Tabriz and Tehran, are indicated as borderline sustainable/unsustainable, is a matter of concern. Both options are 
considered to be, and are stated as, sustainable by their proponents. However, the results indicate that they are only potentially sustainable with an effective EMP and cost management strategy in place.

Recycling has been much vaunted as necessary to preserve environmental resources and prevent further impacts upon the environment. However, the results suggest that recycling is far from the sustainable option stated. Recycling appears to have just as many problems and impacts as landfills without proper environmental management in place. Therefore, there are questions concerning how waste disposal and management can be undertaken in a way conducive towards achieving sustainability. This requires how to recycle waste through the effective management of reducing impacts and the economic/financial costs involved.

In all of the options in an unmitigated state highlighted, for both Tabriz and Tehran, there are significant issues concerning their unsustainability or sustainability. This is matter for all to be concerned with. It only stresses the importance of developing improvements in technique and process to manage waste in a sustainable way-through a co-evolutionary relationship between the environment and humans.

\section{Conclusion}

This paper has applied a revised mathematical model to the original RIAM results of Taheri et al. (2014). This was conducted in order to determine the potential sustainability or unsustainability of four unmitigated options at the Tabriz MSW disposal site in Iran.

The results indicated that none of the options in the unmitigated state were sustainable. Of the three alternatives being considered for Tabriz MSW disposal sitesanitary landfill, composting and recycling, all would require a substantial management plan to make them sustainable. The issue of operational and management costs, particularly in relation to composting and recycling, was identified as a significant barrier towards achieving and maintaining sustainability. The results for Tabriz were then compared to currently unpublished research on a MSW disposal and processing site near Tehran, conducted by the authors. The results have overall indicated that there are significant questions, specifically concerning the potential value of current techniques available for achieving sustainable waste management.

Acknowledgments The authors wish to express their sincere thanks to Mr. Engr. Mohammad Taheri for his support in the preparation of the scoping data. The authors also wish to thank Mr. Engr. Shahin Rahimoghli for his assistance and kindness in giving permission to use the landfill scoping data, as well as providing additional materials and photographs. This research has received no financial support.

\section{References}

Chaudhary BK (2008) Continuous anaerobic digestion of municipal solid waste in thermophilic conditions. Masters thesis, Asian Institute of Technology. Thailand

Gholamalifard M, Mirzaei M, Hatamimanesh M, Riyahi Bakhtiari A, Sadeghi M (2014) Application of rapid environmental impacts assessment matrix and Iranian matrix in environmental impact assessment of solid waste landfill of Shahrekord. J Shahrekord Univ Med Sci 16(1):31-46

Gholamalifard M, Phillips J, Jalili GM (2016). Evaluation of unmitigated options for municipal waste disposal site in Tehran, Iran using an integrated assessment approach. J Environ Plann Manage. doi:10.1080/09640568.2016.1181610

Hassanvand MS, Nabizadeh R, Heidari M (2008) Municipal solid waste analysis in Iran. Iran J Health Environ 1(1):9-18

Memon MA (2010) Integrated solid waste management based on the 3R approach. J Mater Cycles Waste Manag 12(1):30-40

Phillips J (2015) A quantitative-based evaluation of the environmental impact and sustainability of a proposed onshore wind farm in the United Kingdom. Renew Sustain Energy Rev 49:1261-1270

Taheri M, Gholamalifard M, Ghazizade MJ, Rahimoghli S (2014) Environmental impact assessment of municipal solid waste disposal site in Tabriz, Iran using rapid impact assessment matrix. Impact Assess Project Apprais 32(2):162-169

Troschinetz AM, Mihelcic JR (2009) Sustainable recycling of municipal solid waste in developing countries. Waste Manag 29(2):915-923

UNEP (United Nations Environment Programme) (2011). Integrated solid waste management (ISWM). Division of Technology, Industry and Economics, International Environmental Technology Centre, Osaka, Japan. http://www.unep.org/gpwm/ FocalAreas/IntegratedSolidWasteManagement/tabid/56457/ Default.aspx

Wang H, Nie Y (2001) Municipal solid waste characteristics and management in China. J Air Waste Manag Assoc 51(2):250-263

WCED (World Commission on Environment and Development) (1987) Our common future. Oxford University Press, Oxford/ New York 